\title{
PERSPECTIVES
}

SCIENCE AND SOCIETY

\section{The influence of the Internet on immunology education}

\section{Nathalie Debard, Pascal Py, Jean-Pierre Kraehenbuhl and Jonathan Fuchs}

Abstract | The potential of the Internet as a medium through which to teach basic and applied immunology lies in the ability to illustrate complex concepts in new ways for audiences that are diverse and often geographically dispersed. This article explores two collaborative Internetbased learning projects (also known as e-learning projects) that are under development: Immunology Online, which will present an Internet-based curriculum in basic and clinical immunology to Swiss undergraduate and graduate students across five campuses; and the OCTAVE project, which will offer online training to an international cadre of new investigators, the members of which are carrying out clinical trials of vaccines against HIV infection.

During the past decade, e-learning (that is, Internet-based learning or online learning) has been adopted by university educators as a way to enhance the teaching of several disciplines. Initially, e-learning mainly consisted of course syllabi or hand-outs that were electronically distributed to students. More recently, multimedia technologies have evolved to support teaching methods that complement or, when feasible, supplant traditional face-to-face instruction. Increasingly, this strategy is being adopted to support learning in basic and clinical immunology. By combining text, animation, video and simulation, teaching using the Internet might facilitate the understanding of complex immunological concepts, such as antigen presentation, T-cell maturation and mucosal immunity. e-learning also encourages teachers and students to communicate through e-mail or designated chat sessions; these methods allow students to pose questions that they might be uncomfortable asking in a classroom setting, particularly if they feel challenged by material that they perceive others to have mastered. In this way, e-learning has the potential to reduce the disparities among individuals or groups of students, while promoting independent learning. Moreover, learning is not limited by the physical proximity of a student to an individual teacher or institution. The Internet offers the potential to expand access to a global panel of experts and fosters collaboration with other students from different cultural backgrounds or work environments. Despite these advantages, the promise of increased accessibility and innovation through e-learning comes at a cost: development and maintenance require considerable institutional resources for supporting expertise in information technology and for engaging faculty members, who might have limited experience in teaching online. Some of these issues are highlighted in TABLE 1.

In 2000, recognizing the potential of Internet-based instruction to enhance learning opportunities in a range of areas, the Swiss government, seven Swiss universities and two institutes of technology collaborated to support the Swiss Virtual Campus (SVC) programme. At an initial cost of $€ 35$ million, the SVC programme supports more than 50 e-learning projects, including a new online curriculum that is intended to teach immunology. The architects of the SVC acknowledged that much of the coursework in basic and clinical immunology at the university level relies heavily on traditional approaches to learning, in which updates to textbooks and curricula often lag behind rapid scientific advances and in which course content is revised on an annual, or less frequent, basis. Moreover, it was increasingly recognized that students are demanding greater flexibility in how and when they prepare for classes. In response to these challenges and the desire to standardize learning opportunities across campuses, Immunology Online (see the Online links box), which is an Internet-based curriculum that targets medical and graduate students, is now under development and will be formally added to the SVC in late 2005. It draws on expertise from all of the participating campuses in both basic and clinical immunology, and it uses unique teaching methods that have been adapted for an online format. Through its learningmanagement system (LMS), which is the platform on which the different methods of teaching are built, a unique learning experience can be tailored to the needs and skill levels of the enrolled students. The LMS can also track the progress of students and allows instructors to evaluate the performance of students as they navigate the curriculum. Immunology Online can be used as part of a 'blended-learning' strategy that combines face-to-face and online learning, or it can be used as an alternative to traditional courses.

Similar efforts to offer online training are being pursued in areas of applied immunology, specifically in HIV vaccine development. Diverse audiences of students from around the world are building the infrastructure that is required to recruit and retain volunteers in clinical trials that evaluate the safety, immunogenicity and efficacy of experimental vaccine candidates. The HIV Vaccine Trials 


\begin{tabular}{|c|c|c|}
\hline Dimension & e-learning & Conventional learning \\
\hline Audience & $\begin{array}{l}\text { Students can hail from several institutions } \\
\text { worldwide; limited class size is preferable } \\
\text { for group-learning activities; class size is } \\
\text { unlimited for individual learning }\end{array}$ & $\begin{array}{l}\text { Often restricted to students } \\
\text { enrolled at one institution; limited } \\
\text { class size is preferable }\end{array}$ \\
\hline $\begin{array}{l}\text { Content } \\
\text { and delivery }\end{array}$ & $\begin{array}{l}\text { Course content is often created } \\
\text { collaboratively and benefits from } \\
\text { several experts and peer review; } \\
\text { multimedia technology can offer } \\
\text { real-time animation and video to } \\
\text { simulate complex concepts; experts } \\
\text { in information technology are required } \\
\text { to post and maintain content; course } \\
\text { faculty members often require further } \\
\text { training in online teaching }\end{array}$ & $\begin{array}{l}\text { Individual faculty members } \\
\text { often develop and deliver their } \\
\text { own course content; access to } \\
\text { animation and video is possible } \\
\text { but is often limited; experts in } \\
\text { information technology are not } \\
\text { required; classroom-based } \\
\text { instruction does not require extra } \\
\text { training of faculty members in } \\
\text { online teaching }\end{array}$ \\
\hline Accessibility & $\begin{array}{l}\text { Computer hardware and software are } \\
\text { required by users; high-speed Internet } \\
\text { access is preferable }\end{array}$ & $\begin{array}{l}\text { Computers and Internet } \\
\text { connections are not required }\end{array}$ \\
\hline Interactivity & $\begin{array}{l}\text { An independent learning style is } \\
\text { favoured; fosters interaction among } \\
\text { students and teachers online; limited } \\
\text { face-to-face contact in distance } \\
\text { learning }\end{array}$ & $\begin{array}{l}\text { Both independent and instructor- } \\
\text { dependent learning styles can be } \\
\text { accommodated; fosters interaction } \\
\text { among students and teachers in } \\
\text { person; considerable face-to-face } \\
\text { contact at one institution }\end{array}$ \\
\hline Flexibility & $\begin{array}{l}\text { Online lectures, case-based learning } \\
\text { or other approaches can be tailored to } \\
\text { the material; learning methods can be } \\
\text { tailored to individual students to meet } \\
\text { learning objectives }\end{array}$ & $\begin{array}{l}\text { Instruction often relies on lecture- } \\
\text { style teaching in a classroom } \\
\text { setting; pace of learning depends } \\
\text { on instructor and student feedback; } \\
\text { learning objectives might or might } \\
\text { not be met by all students }\end{array}$ \\
\hline
\end{tabular}

Network (see the Online links box), which is supported by the National Institute of Allergy and Infectious Diseases (United States), engages a global network of investigators who are dedicated to speeding the delivery of an effective preventive vaccine against infection with HIV. Spread across 4 continents at 30 clinical-trial sites, the network faces a challenge to train its newest investigators and affiliated laboratory staff to participate in protocol development and implementation. To support this essential capacity-building effort, the network has spearheaded a new online training programme in collaboration with the EuroVacc Foundation (see the Online links box) and other partner institutions. The LMS platform mentioned earlier will also be utilized by this programme, which is known as the Online Collaborative Training for AIDS Vaccine Evaluation project (OCTAVE project; see the Online links box). The OCTAVE project will deliver training in priority areas, including good clinical and laboratory practices, HIV pathogenesis and HIV vaccinology. The use of e-learning by the OCTAVE project will complement, rather than replace, face-to-face training offered by trial sponsors. This blended approach to learning, although resource intensive, responds to the need for on-site face-to-face training visits, which are particularly useful for training in laboratory methods, while acknowledging the value of reinforcing key concepts after the trainers have departed. This article explores the advantages and limitations of e-learning compared with conventional approaches to teaching, and it details how Immunology Online and the OCTAVE project plan to reach their target audiences in the coming years.

\section{Pros and cons of e-learning}

Recent studies indicate that students are satisfied with e-learning, lending support to this method as a viable alternative to conventional teaching methods in basic science and applied public-health practice ${ }^{1,2}$. However, many university-based immunology curricula still rely exclusively on several individual instructors who develop lecture-orientated courses independently of one another without attempting to harmonize the content. This vertical approach to course development (FIG. 1) upholds the autonomy of each individual teacher and his or her control of all phases of the educational process, but it complicates broader attempts to standardize curricula across institutions, which is a goal of the SVC and other groups. Conventional teaching models are also resource intensive; to cover basic and clinical immunology, several faculty experts are required, each of whom must repeat the process of designing and delivering one or more courses. Moreover, conventional models can affect how students learn over time as they encounter different instructors whose courses might diverge from institutional learning objectives.

e-learning offers a strategy that can standardize the content produced by experts who are collaborating within or across institutions. This requires a coordinated curriculum-planning process that promotes shared learning objectives and facilitates the creation of up-to-date content. Moreover, depending on the capacity of the Internetbased platform that is used, it might be possible to track centrally the learning of an individual student and to provide feedback to both the student and the instructor regarding whether the course objectives have been met.

There are, however, notable limitations when using an Internet-based approach to teach immunology, many of which are applicable to e-learning in general. Sophisticated animation, which can enhance learning of the biological sciences, requires students to have access to individual computers with sufficient data-handling capacity and high-speed connections to the Internet if they are to appreciate properly the content of a web site. Also, text-heavy web sites can be difficult to read on a computer screen. Furthermore, there is the risk of reducing social interactions, which can foster learning both among students and between students and teachers. To remedy this, Internetbased communication tools, such as online chat groups and forums, have been used effectively in distance learning and can be adopted by new online courses to optimize blended approaches to learning.

\section{Customization using an LMS}

The ability of the Internet to foster an integrated approach to learning immunology depends, in part, on the technological capacity of the platform that is used. The LMS platform, which is used by both Immunology Online and the OCTAVE project, begins with a reference curriculum that is assembled by several experts. This core curriculum offers succinct overviews of peer-reviewed material that prepare students for case-based exercises or other active methods of learning. The components of the curriculum and the order in which they are accessed can be customized. Instructors or online tutors can organize 


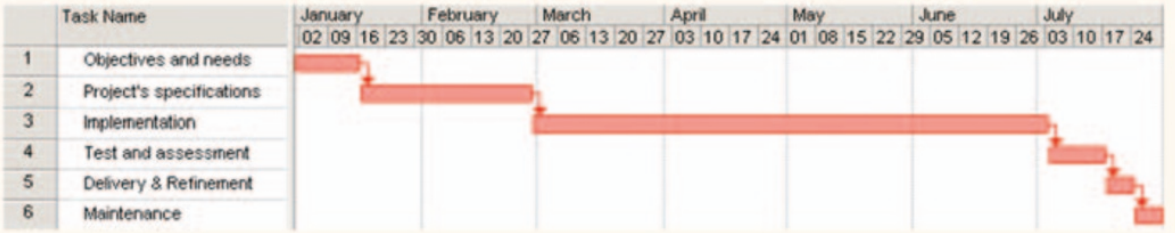

Figure 1 | A conventional model of course development and delivery. This sample timeline describes a conventional approach to developing a course in immunology. Six basic steps (shown as sequential red bars) are required of the course faculty members. These steps include translating institution-sanctioned learning objectives, developing a course syllabus that meets the specifications of the project, teaching the class, and assessing student learning. On the basis of the opinions of the instructor about how the course was delivered and any feedback received from students, the course is subsequently refined and maintained.

content in a range of ways, and students can complete the required elements in a time frame that is compatible with the guidelines of an institution. Course outlines, learning objectives and methods of assessment can be modified before, or even during, learning sessions. In addition, the LMS can help both the instructor and the student to keep track of progress, which ensures that students proceed to higher level material only after they have mastered the fundamental concepts. Moreover, to recreate the interactivity of a classroom, the LMS supports several functions, including online chatting, note-taking, hand-outs and quizzes. These functions can be navigated easily by users of Immunology Online, as illustrated in FIG. 2.

\section{Immunology Online}

Immunology Online is an Internet-based immunology course for students of immunology who are undertaking a bachelors, masters or doctoral degree. The programme was initially conceived for Swiss students; however, through a collaboration with the World Health Organization, content will also be shared in the future with medical students and health-care personnel in Africa, Asia and South America. To be selected by the Steering Committee of the SVC, e-learning project proposals are required to involve at least three Swiss universities. Immunology Online federated the five Swiss medical schools around the same educational project and fostered the development of harmonized learning objectives by faculty members of these institutions. The broad content of Immunology Online is divided into basic and clinical immunology: the basic immunology content comprises six modules that cover all aspects of fundamental immunology, ranging from antigen sampling and presentation to leukocyte trafficking, cytokine networks, and innate and adaptive immunity; the eight modules of clinical immunology content cover inflammation, autoimmunity, immune deficiencies, allergy, transplantation, immunity to infections, tumour immunology and vaccinology. The transplantation module has been completed and will be made available to students in late 2005, whereas the other seven modules will be launched in January 2006.

Although there are already some excellent web sites that review concepts in immunology (TABLE 2), their interactivity varies considerably, ranging from simple course notes that are provided in a Microsoft Office PowerPoint format to online textbooks that combine text, illustrations and high-quality animations. The Integrated Medical Curriculum (see the Online links box) uses a combination of these elements to teach clinical immunology through the Internet. However, we are not aware of any educational web sites that review basic and clinical immunology using the wide range of learning strategies that are exploited by Immunology Online. Specifically, Immunology Online will offer three distinct approaches to learning: clinical, case-orientated instruction; annotated article-based learning; and a structurefunction approach. The last of these uses detailed animation to provide an in-depth exploration of the structural organization of lymphoid organs and their respective roles in the development of an immune response. Each of these approaches is described briefly in this section.

Clinical, case-orientated learning encourages small groups of students to analyse and explain relevant immunological principles. As students proceed through a case study, an Internet-based application, rather than a live tutor, assists them in identifying gaps in their knowledge and highlights targeted reviews of appropriate background content that will help them to achieve predefined learning objectives. This approach was developed so that university partners who already use problem-based learning in their courses could continue to do so. The present version of the Internet-based application has benefited from feedback from educational experts, and it continues to undergo improvements.

Annotated article-based learning offers an opportunity for students to familiarize themselves with the content and format of original scientific publications. Various tools have been created to help students to read and interpret the literature. These include the following: guidelines for reading, evaluating and presenting the findings of an article; active links to specific pages of laboratory techniques or other relevant content; and an extensive glossary of terms. This method of learning is particularly valuable for students who are planning careers in basic or clinical research because it helps them to build lifelong learning skills and promotes greater insight into the design of experimental procedures.

The structure-function approach makes use of high-quality illustrations and animations to enhance traditional textbook learning. For example, students reading about how antigens are presented to $\mathrm{T}$ cells can also visually track the journey of a cell from the bone marrow through the thymus to the periphery, where the complex T-cell-macrophage interplay that occurs can be viewed on a microscopic level.

All of these approaches adhere to a 'onepage-one-concept' model of design. This supports the easy navigation and clear presentation of information, which are important incentives for learning. Students are encouraged to explore the entire web site during their studies, and this approach takes into account that, at any one time, students might review content that is not applicable to their present learning objectives. To help students to keep on track, the LMS offers a tool that will allow them to see whether the pages that they have visited are validated components of their learning plan. In addition, Immunology Online relies on the LMS to support a range of evaluation strategies, including quizzes (designed with the Questionmark Perception assessment system), that function as an assessment interface, as well as a teaching tool. Moreover, Immunology Online allows instructors to moderate both one-on-one and group forums that can promote interaction between students and some of the top specialists in the discipline.

Access to Immunology Online will be free to Swiss universities but will be password protected. (A username and password can be obtained by sending an e-mail to 


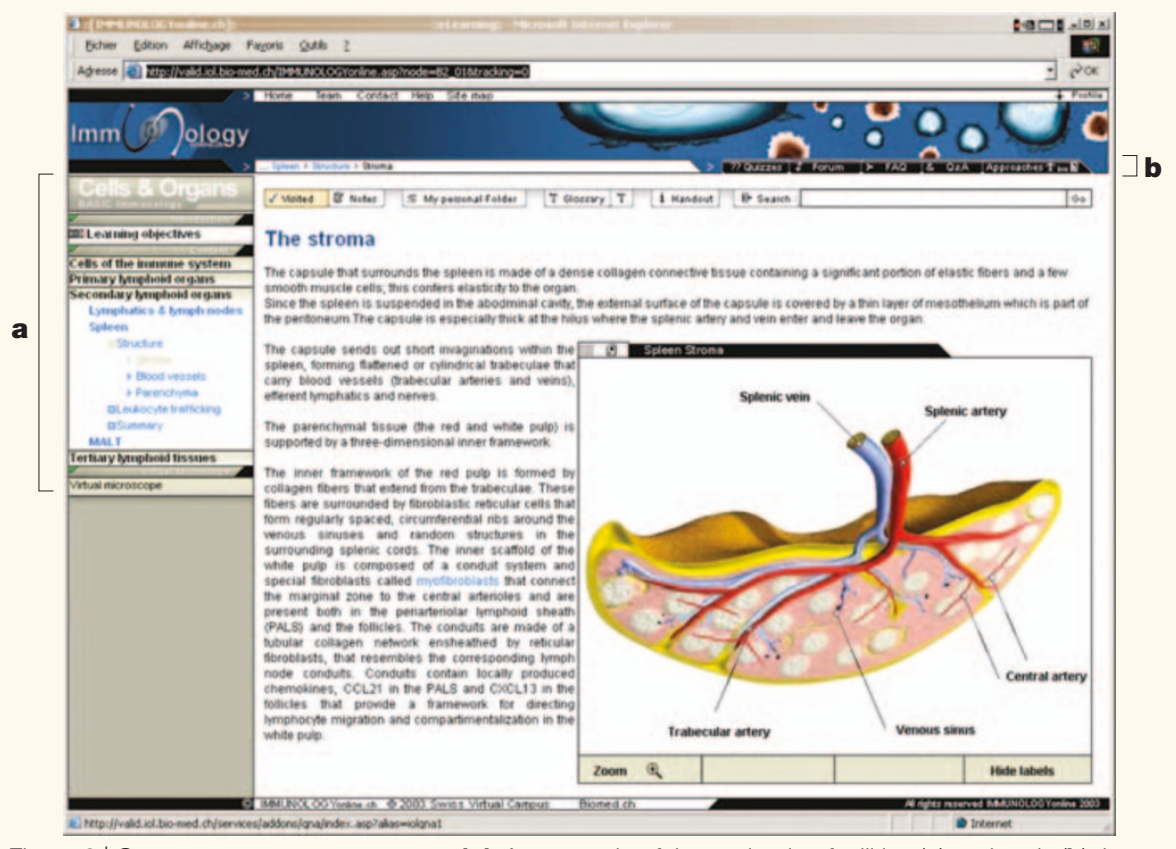

Figure 2 | One-page-one-concept model. An example of the navigation facilities (a) and tools (b) that are available on Immunology Online is shown.

support@iol.ch.) Although parts of the web site have been previewed by students at the University of Lausanne and the University of Geneva, as well as students in resourcepoor countries such as Cuba and Niger, it is anticipated that the basic immunology section will not be completed until late 2005 and that the clinical immunology section will be launched in early 2006. In addition, it is envisaged that broader access will be offered through institutional licensing agreements subject to negotiation.

\section{The OCTAVE project}

The HIV pandemic claimed more than 3 million lives in 2003, and there are an estimated 14,000 new infections daily ${ }^{3}$, which reinforces the urgent need for an effective preventive vaccine. To further this goal, several public and private institutions worldwide are engaged in the iterative process of testing vaccine candidates (see International AIDS Vaccine Initiative database of AIDS vaccines in human trials in the Online links box). Human trials must be carried out in accordance with accepted regulatory and ethical standards, to ensure the safety of healthy volunteers. To support this endeavour, well-trained personnel, including new clinical investigators from the resource-poor nations that are most heavily burdened by HIV/ AIDS, are particularly sought to participate in the design and implementation of these studies. However, many new investigators lack experience in clinical trials and lack formalized training in research methods, which creates a potential gap in the knowledge and expertise that are required to develop and implement vaccination protocols.

Considerable resources have been committed by trial sponsors and governments to facilitate technology transfer to investigators and laboratory specialists in the developing world. Local, as well as international, fellowship programmes and research internships are important components of this effort. However, the Internet can also be used as a resource to deliver training to key personnel in geographically dispersed locations. Indeed, distance education using the Internet has been successfully implemented to train service providers to offer tailored interventions for preventing infection with $\mathrm{HIV}^{4}$, and similarly, it is thought that e-learning approaches can be built and maintained to support staff members who are dedicated to advancing the HIV vaccine-development effort. The OCTAVE project has made important steps towards this goal by addressing key training priorities, including good clinical practices, good clinical laboratory practices, laboratory methodologies, vaccinology and HIV immunopathogenesis. Contributing authors that represent a wide range of collaborating organizations and industry partners will provide relevant content for use by a diverse audience of investigators and support staff.
Similar to Immunology Online, the OCTAVE project will use the LMS to provide various interactive training experiences. For example, plans for the laboratory assays and methodology section of the web site will encourage users to enter a virtual laboratory and assume the role of a technician, investigator or member of a quality assurance team. Students can choose to enter different areas of the laboratory, where they can learn more about flow cytometry, peripheral-blood mononuclear-cell processing and HIV diagnostics, among other topics. It is hoped that this Internetbased resource will be used to help to prepare staff for on-site training visits by trial sponsors and to reinforce key messages and techniques thereafter, when the staff of the clinical facilities are expected to carry out these functions autonomously.

Training in good clinical practice will rely on article- and case-based learning to clarify the responsibilities of the investigator, which are outlined in regulatory guidelines from the International Conference on Harmonization and in The Code of Federal Regulations (United States). In addition, vaccinology training will use self-directed and tutor-assisted, case-based instruction to help investigators to integrate preclinical safety and immunogenicity data, thereby building a rationale for moving a hypothetical candidate HIV vaccine into clinical trials. This training will also be informed by relevant background information that is contributed by experts in HIV immunopathogenesis. Finally, the project is committed to involving investigators from resource-poor nations at all levels of programme development, including content creation, peer review, and evaluation, to confirm the relevance and usefulness of the curriculum in local contexts. This pilot programme was initiated in mid-2004, and we hope to launch pilot modules of the laboratory methodology training by the end of 2005.

\section{Comment}

Interest in e-learning programmes, such as Immunology Online and the OCTAVE project, reflects a broader trend across a range of disciplines for using the Internet to provide up-to-date educational information to a broad audience in an accessible user-friendly way. These activities, among others, promote lifelong learning for individuals who are committed to continuing to build their skills in response to a rapidly changing society ${ }^{5}$. In July 2004, the European Parliament and the Council of 


\begin{tabular}{|c|c|c|c|}
\hline Programme & Author & Access & URL \\
\hline $\begin{array}{l}\text { Basic } \\
\text { Immunology }\end{array}$ & $\begin{array}{l}\text { V. Klimov, Tomsk } \\
\text { Polytechnic University } \\
\text { (Tomsk, Russia) }\end{array}$ & $\begin{array}{l}\text { Password } \\
\text { protected }\end{array}$ & $\begin{array}{l}\text { http://www.immunology.klimov. } \\
\text { tom.ru/index.html }\end{array}$ \\
\hline $\begin{array}{l}\text { BIOL } 230 \\
\text { Microbiology } \\
\text { Lecture Guide }\end{array}$ & $\begin{array}{l}\text { G. E. Kaiser, Community } \\
\text { College of Baltimore } \\
\text { County (Catonsville, } \\
\text { Maryland, USA) }\end{array}$ & Free & $\begin{array}{l}\text { http://student.ccbcmd.edu/courses/ } \\
\text { bio141/lecguide/index.html }\end{array}$ \\
\hline $\begin{array}{l}\text { Microbiology } \\
\text { and Immunology } \\
\text { Online }\end{array}$ & $\begin{array}{l}\text { A. Ghaffar, G. Mayer, } \\
\text { W. Bowers and R. Hunt, } \\
\text { University of South } \\
\text { Carolina (Columbia, } \\
\text { South Carolina, USA) }\end{array}$ & Free & $\begin{array}{l}\text { http://pathmicro.med.sc.edu/book/ } \\
\text { immunol-sta.htm }\end{array}$ \\
\hline $\begin{array}{l}\text { Essentials of } \\
\text { Immunology }\end{array}$ & $\begin{array}{l}\text { A. C. Reese, Medical } \\
\text { College of Georgia } \\
\text { (Augusta, Georgia, USA) }\end{array}$ & $\begin{array}{l}\text { Password } \\
\text { protected }\end{array}$ & http://imc.meded.com/ \\
\hline $\begin{array}{l}\text { Molecular } \\
\text { Immunology }\end{array}$ & $\begin{array}{l}\text { D. Focosi, Santa Chiara } \\
\text { Hospital (Pisa, Italy) }\end{array}$ & Free & http://www.mi.interhealth.info \\
\hline $\begin{array}{l}\text { Kimball's Biology } \\
\text { Pages }\end{array}$ & J. Kimball & Free & $\begin{array}{l}\text { http://users.rcn.com/jkimball. } \\
\text { ma.ultranet/BiologyPages }\end{array}$ \\
\hline $\begin{array}{l}\text { Infection and } \\
\text { Immunity }\end{array}$ & $\begin{array}{l}\text { A. Cann, University of } \\
\text { Leicester (Leicester, UK) }\end{array}$ & Free & $\begin{array}{l}\text { http://www-micro.msb.le.ac.uk/ } \\
\text { mbchb/default.html }\end{array}$ \\
\hline
\end{tabular}

the European Union adopted ambitious proposals for a new generation of programmes - entitled Lifelong Learning - in the fields of education and culture, and these include an e-learning action plan. The Council of the European Union predicts that at least $12.5 \%$ of the adult, working-age population will participate in lifelong learning activities $^{6}$, of which e-learning initiatives will feature prominently, at a cost of $€ 44$ million in the next two years ${ }^{7}$. This reinforces the stated commitment of the European Union to work towards an 'advanced knowledge' society with sustainable development, job creation and greater social cohesion. Many people assert that this goal could be reached partly by harmonized educational and training opportunities. This approach will promote considerable growth in Internet-based learning.

As e-learning programmes are put forward, particularly those that are explicitly focused on reaching audiences in resourceconstrained settings, it is important to acknowledge some logistical and developmental challenges. High-speed Internet access is required to obtain full benefit from the functionality of these web sites, and although such connections are increasingly available, they are by no means universal. A careful inventory of the hardware that is available at the institutions that intend to use these programmes should be carried out by sponsoring universities and research organizations to anticipate and plan for future investment in information technology.
In addition, considerable resources, both financial and human, are needed to conceive of, and develop, web sites that incorporate innovative learning strategies. However, both the creators and funders must have the foresight to plan the scope of e-learning resources so that such web sites can be adequately maintained. Consistent investment in infrastructure, including information technology and methods to track content creation and reliability, are therefore crucial. Finally, soliciting input from representatives of the target audience throughout the development and implementation phases of web sites does not guarantee the rapid uptake and applicability of the educational programme. e-learning initiatives should carry out process and impact evaluation, when feasible, and can incorporate experimental methods that compare different teaching approaches among diverse student populations, the results of which can then inform future course design ${ }^{8}$. Ultimately, it is hoped that programmes such as Immunology Online and the OCTAVE project will promote continuing, independent learning for both students and practitioners of basic and applied immunology.

Nathalie Debard and Jean-Pierre Kraehenbuhl are at the EuroVacc Foundation, Swiss Institute for Experimental Cancer Research, Chemin des Boveresses 155, CH 1066 Epalinges, Switzerland, and at the Division of Immunology and Allergy, Centre Hospitalier Universitaire Vaudois, CH 1011 Lausanne, Switzerland.
Pascal Py is at the EuroVacc Foundation, Swiss Institute for Experimental Cancer Research, Chemin des Boveresses 155, CH 1066 Epalinges, Switzerland, and at the Department of Psychiatry Research, University of Zurich, Zurich 8032 Switzerland.

Jonathan Fuchs is at the HIV Research Section, San Francisco Department of Public Health, 25 Van Ness Avenue, Suite 500, San Franscisco, California 94102, USA, at the Department of Medicine, University of California, San Francisco, California 94117, USA, and at the HIV Vaccine Trials Network, Fred Hutchinson Cancer Research Center, Seattle, Washington 98109, USA.

Correspondence to J.-P.K. e-mail: jean-pierre.kraehenbuhl@isrec.ch doi:10.1038/nri1687 Published online 19 August 2005

1. Johnson, S. D., Aragon, S. R., Shaik, N. \& Palma-Rivas, N. Comparative analysis of learner satisfaction and learning outcomes in online and face to face learning environments. J. Interact. Learn. Res. 11, 29-49 (2000).

2. Davis, M. V., Sollecito, W. A., Shay, S. \& Williamson, W. Examining the impact of a distance education MPH program: a one-year follow-up survey of graduates. J. Public Health Manag. Pract. 10, 556-563 (2004)

3. The Joint United Nations Programme on HIV/AIDS. AIDS Epidemic Update: 2003 (The Joint United Nations Programme on HIV/AIDS, Geneva, 2003).

4. Kelly, J. A. et al. Distance communication transfer of HIV prevention interventions to service providers. Science 305, 1953-1955 (2004).

5. Serres, M. The Troubadour of Knowledge (Univ. Michigan Press, Ann Arbor, 1997).

6. Europa. Education council agrees on European benchmarks [online], <http://europa.eu.int/rapid/ pressReleasesAction.do?reference=IP/03/ 620\&format=HTML\&aged=0\&language $=E N \&$ guil Language $=e n>$ (5 May 2003).

7. European Parliament and the Council of the European Union. Adopting a multiannual programme (2004 to 2006) for the effective integration of information and communication technologies (ICT) in education and training systems in Europe (eLearning Programme) (2318/200/EC). Official J. Eur. Union L345/9 (31 Dec 2003).

8. Artelt, C., Baumert, J., Julius-McElvany, N. \& Peschar, J. Learners for Life - Student Approaches to Learning: Results from PISA 2000 (Organisation for Economic Co-operation and Development, Paris, 2003).

Acknowledgements

N.D. is supported by the University of Lausanne (Switzerland) and the Federal Office for Education and Science (Switzerland). P.P. and J.-P.K. are supported by the EuroVacc Foundation (Switzerland) and the Office of AIDS Research at the National Institutes of Health (United States). J.F. is supported by the National Institute of Allergy and Infectious Diseases (United States).

Competing interests statement

The authors declare no competing financial interests.

\section{(0) Online links}

\section{DATABASES}

The following terms in this article are linked online to: Infectious disease information:

http://www.cdc.gov/ncidod/diseases/index.htm HIV

\section{FURTHER INFORMATION}

EuroVacc Foundation: http://www.eurovacc.org HIV Vaccine Trials Network: http://www.hvtn.org Immunology Online: http://www.iol.ch Integrated Medical Curriculum:

http://meded.utmb.edu/CurrentStudentlnfo.htm International AIDS Vaccine Initiative database of AIDS vaccines in human trials: http://www.iavireport.org/trialsdb OCTAVE project: http://octave.bio-med.ch Access to this interactive links box is free online. 